\title{
Resource Use Efficiency and Factors Affecting Land Allocation for Wheat (Triticum aestivum L.) Production in Bangladesh
}

\author{
Basanta Kumar Barmon* and Mahfuzul Islam \\ Department of Economics, East West University, Dhaka-1212, Bangladesh \\ *Corresponding author and Email: bkbarmon@yahoo.com
}

Received: 2 November 2016

Accepted: 12 June 2017

\begin{abstract}
The present study aimed to estimate the resource use efficiency and identify the factors affecting land allocation for wheat production in Bangladesh. Primary data were randomly collected from 183 wheat producers from three Upzillas of Natore district. The results revealed that farmers had experienced decreasing return to scale in wheat production. Farm area, seed cost and labor cost were the main factors that positively, and irrigation negatively affected wheat production. The sampled farmers failed to show their efficiency in using the resources in wheat cultivation. There was further opportunity to increase wheat production using more seed, chemical fertilizers, manure and pesticides. However, there was no further scope to increase wheat production by using irrigation, land preparation and labor inputs. The study also revealed that farmers' age, education, wheat farming experience, location and family size significantly affected the probability of land allocation in wheat production. Soil type in the study areas played a vital role in the decision process of wheat cultivation. It could be concluded that proper utilization of inputs can increase wheat in Bangladesh.
\end{abstract}

Keywords: Resource use efficiency, affecting factor, land allocation, wheat production, Bangladesh.

\section{Introduction}

Wheat (Triticum aestivum L.) is the second main cereal food grain item after rice which has a significant contribution on Bangladesh economy in terms of production, food security and employment generation (BBS, 2013). Since the independence of Bangladesh in 1971, sustained government investment on irrigation facilities, the introduction of new seeds, extensive agricultural research, rural infrastructure, application of modern agricultural inputs and extension services has helped Bangladeshi farmers to achieve a dramatic increase in food production. Bangladesh is now nearly selfsufficient in rice production (IRRI, 2014). Wheat consumption has increased over the decades as people has become more health conscious and it is being used in the industrial sector to make biscuits, bread, and other snacks (Karim et al., 2010). The dietary habit of people of Bangladesh has changed to a considerable extent during the past decades, wheat has now become an indispensable food item in the food basket of the people of Bangladesh and it continues to fill the food gap caused by the possible failure of rice production. Within a period of 40 years, wheat has been firmly established as a secure crop in Bangladesh, impacted by stable market price, favorable weather condition and available supply of modified seeds (Karim et al., 2010). Two million farmers are currently involved in the wheat production (Karim et al., 2010). Demand for wheat rises as lifestyle changes. A vast 
spread of easy or flour-made fast foods in the urban and semi-urban areas has boosted demand for flour, leading to a rise in the overall supply of wheat. In the last one decade, wheat supply to domestic market almost doubled, it increased to 42 lakh tonnes from 22 lakh tonnes during the fiscal 2013-14 (BBS, 2014). In this situation, to meet the demands of an increasing population and to secure future food security need to produce more wheat. Like other food grains, the wheat production could be increased efficiently by utilizing the productive inputs such as land, labour and capital. As there is limited scope to increase of wheat production due to lack of cultivatable area, production can be increased by increasing the technical efficiency of wheat with the existing technology.

Numerous research have been conducted on the adopting factors of agricultural crop production in African and Asian countries (Adesina and Baidu-Forson, 1995; Bakh and Islam, 2005; Baidu, 1999; Batz et al., 1999; Forson, 1999; Gebresilassie and Bekele, 2014; Grisley and Mwesigwa, 1994; Hasan and Islam, 2010; Mussei et al., 2001; Poison and Spencer, 1991; Strauss et al., 1991; Ransom et al., 2003; Wilson et al., 2001; Wubeneh, 2001). Some sporadic researches have also been carried out on technical efficiency (Kaur et al., 2010), constraint to land and water productivity (Mudasser et al., 2001), adopting factors of wheat production (Nowak, 1992) and technological impacts on wheat cultivation in India (Tripathi et al., 2013). Some researchers has conducted research on the different aspects of wheat cultivation in Bangladesh such as technical efficiency (Kamruzzaman and Islam, 2008; Rahman et al., 2002), forecasting of wheat production (Karim et al., 2010), climate change and its impacts on technical efficiency of wheat production (Tasnim et al., 2015) and affecting factors of wheat production in Bangladesh (Rahman, 2003). However, the estimation of resource use efficiency and affecting factors of land allocation of wheat production in
Bangladesh has been received less attention. Therefore, the present study aimed to estimate the resource use efficiency and affecting factors of land allocation of wheat production in Bangladesh. The findings of the present study are expected to be helpful benchmark information for economists, researchers, as well as policy makers and the study will provide beneficial information for the further development of wheat production in Bangladesh.

\section{Methodology}

\subsection{Selection of the study area}

The selection of appropriate study area is the most important part of farm survey. The area in which a farm survey is conducted relies on the specific purpose of the survey and possible cooperation from the respondents. Wheat is cultivated almost all over the country, but there are some areas where wheat grows well. Soil and weather condition of some part of the country is very much suitable for wheat cultivation. In the northern region of Bangladesh namely; Rangpur, Dinajpur and Natore district are the advantaged areas where wheat grows well and that area largely cover about $25 \%$ of the total wheat producing areas (BBS, 2014). Therefore, Baghatipara, Boraigram and Lalpur upzilla of Natore district were selected purposively for this study. The study areas are shown in figure 1.

\subsection{Sources of data}

Primary data were used in this study. Data were collected through structured pre-tested questionnaire. A total of 183 wheat producers were interviewed in this study where 60 from Baghatipara, 63 from Boraigram and 60 Lalpur Upzilla of Natore district. A simple random sampling technique was applied to collect necessary socio-economic information of wheat producers along with the data on inputs and outputs of wheat production. The survey was conducted during the period of April-May, 2016. After collecting data, a necessary modification and editing were made. 


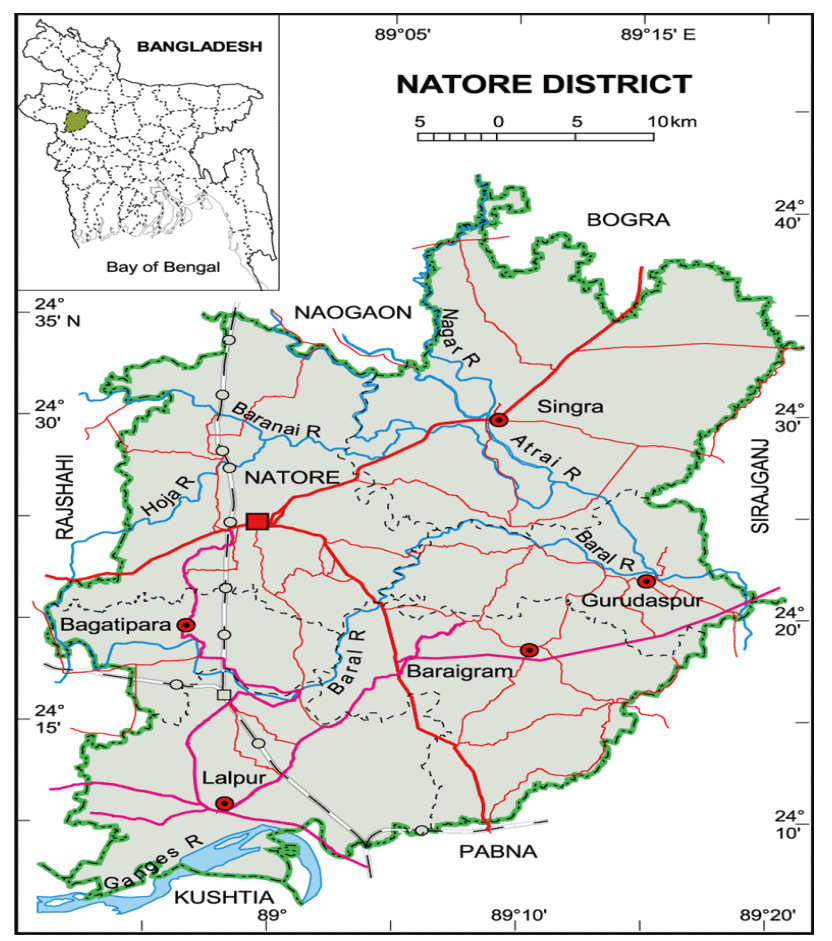

Figure 1. Map of study districts in Bangladesh

\subsection{Analytical techniques}

\subsubsection{Estimation of Cobb-Douglas production function}

The following Cobb-Douglas production function was used to estimate the marginal value of inputs those were used in wheat cultivation in the study areas.

$$
\ln Y=\beta_{0}+\beta_{1} \ln X_{1}+\beta_{2} \ln X_{2}+\beta_{3} \ln X_{3}+\beta_{4} \ln X_{4}+\beta_{5} \ln X_{5}+\beta_{6} \ln X_{6}+\beta_{7} \ln X_{7}+\beta_{8} \ln X_{8}+u_{i} \ldots \ldots .1 X
$$

Where,

$\mathrm{Y}=$ Output of wheat (taka)

$\mathrm{X}_{1}=$ Farm size (hectare)

$\mathrm{X}_{2}=$ Seed cost (taka)

$\mathrm{X}_{3}=$ Irrigation cost (taka)

$\mathrm{X}_{4}=$ Land preparation cost (taka)

$\mathrm{X}_{5}=$ Pesticides cost (taka)

$\mathrm{X}_{6}=$ Manure cost (taka)

$\mathrm{X}_{7}=$ Chemical fertilizer cost (taka)

$\mathrm{X}_{8}=$ Labor cost (man-day; which is equal to 8 working hour per day)

Where, $\beta_{0}$ is intercept and $\beta_{1}, \beta_{2}, \beta_{3}, \beta_{4}, \beta_{5}, \beta_{6}, \beta_{7}, \beta_{8}$ are the coefficients of the regression.

$u_{i}$ is normally and independently distributed with zero mean and constant variance. 


\subsubsection{Resource use efficiency}

Under the perfect competitive market, marginal value product (MVP) is equal to their marginal factor cost (MFC) and it can be used to estimate whether the resources used in agriculture production farming was efficient or not. In general, the producers would choose the input levels that maximize the economic profit (TRTC). The MVP of an input would be estimated, the coefficient of production elasticity is multiplied by the output-input ratio of the geometric mean level, which can be shown in the following formula:

$$
M V P=\frac{\overline{Y_{i}}}{\overline{X_{i}}} \cdot \beta_{i}
$$

Where,

$$
\begin{aligned}
\beta_{i} & =\text { regression coefficient of input } X_{i} \\
\bar{X}_{i}= & \text { mean value (geometric mean) of } X_{i} \\
& \text { variable input } \\
\bar{Y}_{i}= & \text { mean value (geometric mean) of gross } \\
& \text { return of wheat production. }
\end{aligned}
$$

The MVPs of various capital inputs were compared with their respective prices. If MVP of an input is higher than the MFC (market price of that input), then increase in input in production system raises output that increases profit. If MVPs of inputs are negative, then there are possibilities of reduction of these inputs and so the production is carried out in the second stage of the production function and the marginal productivities of these inputs become negative. On the other hand, positive MVPs represent the possibilities of further increase in inputs which will raise output as well as profit.

Profit will be maximized if the inputs are used efficiently and it is efficient when the ratio of MVP to MFC will be 1 (one) or, in other words, MVP and MFC for each input will be equal. The ratio of MVP to MFC for each input is compared to test the resource use efficiency in wheat production and the value will be 1 if $M V P / M F C=1$ (Gujarati, et. al., 2012).

\subsubsection{Estimation of Tobit model}

Among the limited dependent variable models widely used to analyses farmers' decisionmaking processes, Tobit analysis has gained importance since it uses all observations, both those are at the limit, usually zero and those above the limit to estimate a regression line, as opposed to other techniques that uses observations which are only above the limit value (McDonald and Moffit, 1980). The Tobit model is proposed by James Tobin (1958) to describe the relationship between a non-negative dependent variable $Y_{i}$ and an independent variable (or vector) $X_{i}$.

Following this perception, Tobit model was used to analysis the factors affecting the allocation of land in wheat production. The maximum likelihood estimation technique of Tobit analysis provides unbiased and consistent parameter estimates and also allows inclusion of more information than logit or probit technique (Tobin, 1958). Unlike the ordinary least squares (OLS) estimator which assumes that

$E\left(Y_{t}\right)=X_{t}^{\prime} \beta$

The estimates of the Tobit models are derived from:

$E\left(Y_{t}\right)=X_{t}^{\prime} \beta F(z)+\sigma f(z)$

Where

$F(z)=$ cumulative standard normal distribution function; $f(z)=$ the standard normal density function of a normal, random variable with mean zero and variance $\sigma^{2} ; \quad \mathrm{z}=$ normal Tobit index $=X \beta / \sigma ; \sigma=$ standard error of the regression $; \beta=$ regression coefficients; $Y_{t}=$ percent of land allocation. Tobit model (McDonald and Moffitt, 1980; Maddala, 1983) that tests the factors affecting the land allocation in wheat production can be specified as follows:

$Y_{t}=X_{t} \beta+U_{t}$

If $X_{t} \beta+U_{t}>0$

$X_{t} \beta+U_{t} \leq 0$

$\mathrm{t}=1,2 \ldots \mathrm{N}$ 
Where:

$Y_{t}=$ The expected amount of land allocated in wheat production;

$\mathrm{N}$ = number of observations;

$X_{t}=$ vector of independent variables;

$\beta=$ vector of unknown coefficients; and

$U_{t}=$ independently distributed error term

assumed to be normal with zero mean and constant variance $\sigma^{2}$

$X_{t}$ is the index reflecting the combined effect of independent $\mathrm{X}$ variables that prevents or helps to take the decision of allocating land for wheat production. The index level $X_{t}$ can be specified as:

$$
Y_{t}=\beta_{0}+\beta_{1} X_{1}+\beta_{2} X_{2}+\beta_{3} X_{3}+\beta_{4} X_{4}+\beta_{5} X_{5}+\beta_{6} D+\varepsilon_{t}
$$

Where:

$\beta_{0}=$ constant;

$X_{1}=$ age of household head (year)

$X_{2}=$ experience of wheat production (year),

$X_{3}=$ family size (number),

$X_{4}=$ Location of wheat cultivation area (rank),

$X_{5}=$ soil type of arable land (rank)

$D=$ Dummy variable (Dummy, 1 if the farmer is educated (at least read), 0 otherwise)

$\varepsilon_{\mathrm{i}}=$ error term.

The model was estimated using the maximum likelihood method of STATA version 13 .

\section{Results and Discussion}

\subsection{Estimation of resource use efficiency in wheat production}

The estimation of resource use efficiency of wheat production by using Cobb-Douglas production function, and marginal value product (MVP) and marginal factor cost (MFC) are briefly discussed in this section.

\subsubsection{Affecting factors of Cobb-Douglas production function in wheat production}

The model parameters in the Cobb-Douglas production function allowed us to compare empirically the impact of input variables on output. Cobb-Douglas production function has been fitted to work out the elasticity values of production of inputs which in turn have been used to calculate their (inputs) marginal value products (MVP) (at their geometric means) for the average farms. The single equation CobbDouglas production has been estimated by the ordinary least square (OLS) method. In this Cobb-Douglas production function, the dependent variable is the output which is the amount of wheat yield accrued from per farm and the explanatory variables are farm size, seed, irrigation, land preparation, pesticides, manure, fertilizer and labor. The definitions and measurements, and descriptive statistics of variables are given in Table 1 and Table 2, respectively.

Table 2 presents the descriptive statistics of the variables based on per farm are used in the multiple regression analysis. The average irrigation cost of wheat production according to per farm was Tk. 321.13 ranging from a minimum of Tk. 96.19 to as high as Tk. 881.78. The mean land preparation cost of the farmer was Tk. 661.28 with a minimum cost of Tk. 160.32 to a maximum cost of Tk. 1763.56. The average pesticide cost of the famer was Tk. 58.90 which varied between zero to Tk. 240.49. The mean seed cost was Tk. 205.88 ranging from minimum of Tk.24.05 to a maximum Tk.598.54. The average manure cost per farm was Tk. 105.53 with a minimum of $\mathrm{Tk} .0 .00$ to a maximum of Tk. 601.21. The mean fertilizer cost of the farm was Tk. 409.74 which varied from Tk. 45.96 to Tk. 1298.62. The average labor cost per farm was Tk. 600.50 that lies between Tk.76.82 to Tk. 1923.89. The average yield per farm was $106.70 \mathrm{Kg}$ and it varies between 13.36 $\mathrm{Kg}$ to $320.65 \mathrm{Kg}$.

The regression coefficients of Cobb-Douglas production function indicate that the elasticity values of an input in production and the sum of these elasticity values indicates the nature of returns to scale. The returns to scale are decreasing, constant and increasing as the sum of 
regression coefficients is less than, equal to or greater than unity, respectively. It can be observed from the table 3 that the sum of the elasticity values of wheat production was 0.95 which were less than unity, indicating that farmers had experienced decreasing return to scale in wheat production in the study area. The values of $\mathrm{R}^{2}$ for wheat production were quite high. These indicate that the variables appearing in the Cobb-Douglas production equations explained quite a high proportion of variations in wheat cultivation they were statistically significant at 1 percent level.
The coefficients of farm area (0.539), seed cost $(0.3412)$ and labor cost (0.309) were positive and statistically significant at 1 percent level, whereas the coefficient of fertilizer cost $(0.189)$ was also positive and statistically significant at 5 percent level. This indicates that farm area, seed cost and labor cost were the main factors that had significant positive impact on wheat production in the cultivation area. In other words, the producers have ample opportunity to increase wheat production using more seed and labor in the production process.

Table 1. Definitions of the variables in the Cobb-Douglas production function

\begin{tabular}{|c|c|}
\hline \multicolumn{2}{|c|}{ Dependent variable } \\
\hline Output & Amount of wheat yield in per farm, measured in kg. \\
\hline \multicolumn{2}{|c|}{ Independent variables } \\
\hline Farm Size & Farm size, measured in hectare. \\
\hline Seed & Cost of seed in wheat production, measured in Tk. \\
\hline Irrigation & Cost incurred by number of irrigation used in wheat cultivation, measured in Tk. \\
\hline Land & Land preparation cost, measured in Tk. \\
\hline \multicolumn{2}{|l|}{ Preparation } \\
\hline Pesticides & Amount of cost needed in pesticides in wheat production, measured in Tk. \\
\hline Manure & Cost of manure, measured in Tk. \\
\hline Fertilizer & Total amount of fertilizer used, measured in Tk. \\
\hline Labor & Cost of labor input engaged in wheat production, measured in Tk. \\
\hline
\end{tabular}

Table 2. Descriptive statistics of input and output of wheat production (Per Farm)

\begin{tabular}{llcccc}
\hline Particulars & Measurement & Mean & Standard Dev. & Minimum & Maximum \\
\hline Irrigation & $\mathrm{Tk}$. & $321.13^{* * *}$ & 180.20 & 96.19 & 881.78 \\
land & & $661.28^{* * *}$ & 341.32 & 160.32 & 1763.56 \\
Preparation & $\mathrm{Tk}$. & 50.56 & 0.00 & 240.49 \\
Pesticide & $\mathrm{Tk}$. & $58.90^{* * *}$ & 133.40 & 24.05 & 598.54 \\
Seed & $\mathrm{Tk}$. & $105.88^{* * *}$ & 133.83 & 0.00 & 601.21 \\
Manure & $\mathrm{Tk}$. & $409.74^{* * * *}$ & 269.28 & 45.96 & 1298.62 \\
Fertilizer & $\mathrm{Tk}$. & $600.50^{* * *}$ & 387.75 & 76.82 & 1923.89 \\
Labor & Man-day/Tk & $106.70^{* * *}$ & 65.69 & 13.36 & 320.65 \\
Output & $\mathrm{Kg}$ & &
\end{tabular}

Source: Field Survey, 2015.

Note: i) Sample Size was 183.

ii) $* * *$ indicates statistically significant at $1 \%$ level. 
The empirical results of the Cobb-Douglas production of wheat cultivation were presented in Table 3.

Table 3. Estimated value of coefficients and related statistics of Cobb-Douglas production function for wheat production

\begin{tabular}{llccc}
\hline Variables & Parameters & Co-efficient & Standard error & t-ratio \\
\hline Constant & $\beta_{0}$ & $2.387 * * *$ & 0.719 & 3.32 \\
Farm size $\left(\ln \mathrm{X}_{1}\right)$ & $\beta_{1}$ & $0.539 * * *$ & 0.117 & 4.61 \\
Seed Cost $\left(\ln \mathrm{X}_{2}\right)$ & $\beta_{2}$ & $0.210 * * *$ & 0.068 & 3.05 \\
Irrigation Cost $\left(\ln \mathrm{X}_{3}\right)$ & $\beta_{3}$ & $-0.214 * * *$ & 0.057 & -3.76 \\
Land Preparation cost $\left(\ln \mathrm{X}_{4}\right)$ & $\beta_{4}$ & -0.077 & 0.048 & -1.58 \\
Pesticides cost $\left(\ln \mathrm{X}_{5}\right)$ & $\beta_{5}$ & -0.001 & 0.002 & -0.40 \\
Manure cost $\left(\ln \mathrm{X}_{6}\right)$ & $\beta_{6}$ & -0.001 & 0.002 & -0.44 \\
Chemical fertilizer cost $\left(\ln \mathrm{X}_{7}\right)$ & $\beta_{7}$ & $0.189 * *$ & 0.098 & 1.93 \\
Labor cost $\left(\ln \mathrm{X}_{8}\right)$ & $\beta_{8}$ & $0.309 * * *$ & 0.072 & 5.55 \\
Sum of elasticities $\beta_{\mathrm{i}}$ & & 0.95 & & \\
$\mathrm{R}^{2}$ & & $0.92 * * *$ & & \\
\hline
\end{tabular}

Source: Field survey, 2015.

Notes: (i) Sample size was 183.

(ii) $* * *$ and $* *$ indicate $1 \%$ and $5 \%$ level of significance, respectively.

However, the coefficient of cost of irrigation was negative (-0.214) and statistically significant at 1 percent level which indicate that irrigation had a significant negative impact on wheat production. The coefficients of the cost of land preparation ($0.077)$, pesticides $(-0.001)$ and manure $(-0.001)$ were negative and they were all statistically insignificant in the wheat production in the study area. The negative coefficient of irrigation, land preparation, pesticides and manure revealed that the farmers expensed excessive amount of money on irrigation, land preparation, pesticides and manure to grow wheat in the study area.

\subsubsection{Resource use efficiency of wheat production}

The marginal value products (MVPs) of various capital inputs were worked out at the geometric mean (GM) levels for the method of application of the wheat cultivation and were compared with their respective prices.

Marginal factor cost (MFC) of all inputs is expressed in terms of an additional taka spent for providing individual inputs in Cobb-Douglas production. Therefore, to calculate the ratio of MVP to MFC the denominator would be one and consequently the ratio would be equal to their MVP of an input in the production process. The marginal value product (MVP) and the ratio of MVP to MFC of wheat cultivation were presented in Table 4. The table shows that none of the marginal value products (MVPs) of inputs was equal to one, indicating that the sampled farmers in the study area failed to show their efficiency in using the resources in wheat cultivation.

From the table 4 it can be observed that, for the wheat cultivation the ratios of MVP to MFC for the cost of seed (0.131) and fertilizer (0.0825) were both statistically significant at 1 percent level. MVP to MFC for pesticides (0.0003), manure $(0.0002)$ were also positive but values were less than one ,which indicated that there was further opportunity to increase wheat production using more seed, fertilizer, manure and pesticides. In case of irrigation cost, the ratio of MVP to MFC was (-0.0285) which was 
statistically significant at 5 percent level and ratio of land preparation cost (-0.0008), labor cost $(-0.0082)$ were also negative, however, they were not statistically significant. These negative values indicated that there was no further scope to increase wheat production by using irrigation, land preparation and labor inputs.

\subsection{Estimation of Tobit model}

\subsubsection{Tobit analysis of land allocation in wheat production}

A number of researches were conducted to find out the factors which determine the allocation of land for improved wheat variety. Gebresilassie and Bekele (2014) examined factors influencing allocation of land for improved wheat variety by small holder farmers in the Northern Ethiopia. They used Tobit model to analyze factors including education level of household head, family size, tropical livestock unit, and distance from the main road and nearest market access to credit services, extension contacts and perception of household towards costs of technology. Similarly Mussei et al. (2001) carried out a research in Tanzania to understand how small scale farmers have allocated land to improved wheat production. They have also used Tobit model to analysis and showed that farm size, family size, and use of hired labor were significant factors affecting the proportion of land allocation to improved wheat cultivation. Similarly, to find out the proportion of land allocation in wheat production, Tobit model was also used in this study. The Tobit model adopted in this study because proportion of land used in wheat production was continuous but truncated between zero and one.

The definitions and measurements of the variables are given in the table 5. Table revealed that the dependent variable is the proportion of land allocated for wheat farming and among the explanatory variables age is proxy for farming experience of a farmers that can erode or generate confidence to allocate land in wheat production. Likewise family size accounts for household farm labor since large household can provide ample labor to manage large scale wheat production. Education boosts the capacity of a farmer in acquiring, processing and utilizing new information which can put an impact to allocate more or less land in wheat cultivation. Location and soil type account for higher or lower wheat yield. Soil type varies location to location. Thus soil quality can influence attitude of a farmer towards allocating land for wheat cultivation.

Table 4. Resource use efficiency in Cobb-Douglas production for wheat cultivation

\begin{tabular}{lccc}
\hline Name of variables & Coefficients & MPV & MVP/MFC \\
\hline Seed Cost $\left(\mathrm{X}_{2}\right)$ & 0.2939 & $0.1316^{* * *}$ & 0.1317 \\
Irrigation Cost $\left(\mathrm{X}_{3}\right)$ & -0.1232 & $-0.0285^{*}$ & -0.0285 \\
Land preparation Cost $\left(\mathrm{X}_{4}\right)$ & -0.0075 & -0.0008 & -0.0008 \\
Pesticides Cost $\left(\mathrm{X}_{5}\right)$ & 0.0003 & 0.0003 & 0.0003 \\
Manure Cost $\left(\mathrm{X}_{6}\right)$ & 0.0003 & 0.0002 & 0.0002 \\
Fertilizer Cost $\left(\mathrm{X}_{7}\right)$ & 0.3689 & $0.0825^{* * *}$ & 0.0825 \\
Labor Cost $\left(\mathrm{X}_{8}\right)$ & -0.0592 & -0.0081 & -0.0082 \\
\hline
\end{tabular}

Source: Field survey, 2015.

Notes: (i) ***and * indicate statistically significant at $1 \%$, and $10 \%$, respectively. 
Table 5. Definition of variables in the Tobit model

\begin{tabular}{ll}
\hline Dependent variable & \\
\hline Land allocation & The proportion of land allocated for wheat farming \\
\hline Independent variables & \\
\hline Age & Age of the farmers, measured in years. \\
Education & Schooling year of the farmer, measured as a binary variable: 1 if the \\
& farmer is educated, 0 otherwise. \\
Experience & Years of experience in wheat farming, measured in years. \\
Family size & Total household members in farm house, measured in numbers. \\
Location & Wheat cultivated area, measured as rank. \\
Soil type & Types of soil used for wheat cultivation, measured as rank. \\
\hline
\end{tabular}

Table 6. Tobit model estimates for land allocation to improved wheat varieties

\begin{tabular}{lcccc}
\hline Variables & Parameters & Co-efficient & Standard error & $\delta E Y / \delta X_{i}$ \\
\hline Constant & $\delta_{0}$ & 0.4524687 & $0.0954362 * * *$ & 0.30033983 \\
Farmer's Age & $\delta_{1}$ & 0.0054848 & $0.0017412 * * *$ & 0.0039766 \\
Farmer's Education & $\delta_{2}$ & -0.0423509 & $0.0254139 *$ & -0.0307058 \\
Wheat Farming Experience & $\delta_{3}$ & -0.0093706 & $0.0024598^{* * *}$ & -0.006794 \\
Family Size & $\delta_{4}$ & -0.015084 & 0.009694 & -0.0109365 \\
Location & $\delta_{5}$ & -0.083614 & $0.0183082 * * *$ & -0.0606229 \\
Soil Type & $\delta_{6}$ & 0.0063636 & 0.0292677 & 0.0046138 \\
Sigma & 0.1985244 & & & \\
Number of positive & 183 & & & \\
observation & $36.59 * * *$ & & & \\
Wald chi-square $(\beta i=0)$ & 24.861723 & & & \\
Log likelihood function & & & & \\
\hline Source: Field survey, 2015. & & & & \\
\hline
\end{tabular}

Source: Field survey, 2015.

Notes: (i) Sample size of Wheat Farmers produces wheat was 183.

(ii) $* * *$ and $*$ indicate 1 percent, and 10 percent level of significance, respectively.

The Tobit model results on the proportion of land allocated in wheat cultivation using the STATA software are presented in table 6. In the table, $\delta E Y / \delta X_{i}$ shows the marginal effect of an explanatory variable on the expected value (mean proportion) of the dependent variable, The Wald chi-square statistic was significant at $\mathrm{p}<0.01$. Among the variables which were used in this analysis - farmers' age, education, wheat farming experience, and location significantly had influenced the probability of land allocation in wheat production.

From the table 6 it can be observed that, a year increase of the age of wheat farmer increased the probability of allocating land to wheat production by 0.39 percent. The main reason to allocate land in wheat production was that the aged farmer does not want to try new crop production in their farming land. Besides aged 
farmer mostly allocate land to produce wheat for their own consumption and to feed their cattle.

Farmers' education decreased the probability of allocating land to produce wheat by 3.07 percent. The main reason to have negative relation between education and wheat farming is that, the educated farmers are more informative to cultivate high earning crops. With proper information they opt for new verities crop which brings high yield as well as earn more profit than cultivating wheat.

Table shows that wheat farmers farming experience results the probability of land allocation decrease by 0.67 percent. Moreover, prevailing price distortion and local government agent are causing farmer to incur loss for producing wheat. That's why experienced farmers are moving to other crop production from wheat cultivation. Change of location in the study areas decreased the probability of allocating land to wheat production by 6.06 percent. Primary reason for reducing land allocation could be the price variability of wheat in the study areas. Farmers cannot sell their produces at the price fixed by the government due to the cartel created by the local buyers. These people who formed the cartel buy wheat crops from the farmer with a lower price than the government offers to the farmer and after buying they resell those crops to the government with a high price. Thus those people who forms cartel earn a huge amount of money in the some part of study areas and farmers suffer a heavy loss after the post-harvesting period which in turn encourages the farmer to change wheat production to other alternative crop production by allocating existing land used for wheat production. Other study shown that lack of access to facilities constitutes a barrier to entry to agricultural market forced farmers' to produce remain at home or sell at lower prices to fulfill their cash needs. Lack of storage facilities increases risk of losses that affect the quality of products and limit the access to markets with high quality standards.
The probability of allocating land for wheat production based on soil type in three regions is 0.46 percent and it indicated that soil type among these regions plays a vital role to take decision of producing wheat by the farmers. The soil of Baghatipara area is ordinarily black loam, which is very fertile for cultivating wheat (BBS, 2014). As a result in this Upazilla farmer allocated more land to wheat production than the other two upazills.

\section{Conclusions}

This study examined the resource use efficiency and factors affecting land allocation of wheat production in Bangladesh. The findings showed that farm area, seed cost and labor cost were the main factors that positively influence wheat production; while irrigation, land preparation, pesticides and manure costs have negative effect of wheat production. The farmers spent excessive amount of money on irrigation, land preparation, pesticides and manure application to grow wheat. None of the MVPs of inputs was equal to one, indicating that the sampled farmers in the study area failed to show their efficiency in using the resources in wheat cultivation. The results indicated that there was no further opportunity to increase wheat production using seed, fertilizer, manure and pesticides.

The demographic variables used in this analysis were farmers' age, education, wheat farming experience and location significantly influenced the probability of land allocation in wheat production. The educated farmers were more informative to cultivate high value crops. With proper information, they opt for new crops which bring high yield as well as more profit than cultivating wheat. Soil type among these regions plays a vital role to take decision of producing wheat by the farmers. It could be concluded that wheat cultivation and production in Bangladesh can be increased through proper utilization of inputs and appropriate allocation of land to wheat cultivation. 


\section{References}

Adesina, A. A., Baidu-Forson, J., 1995. Farmers Perceptions and Adoption of New Agricultural Technology: Evidence from Analysis in Burkina Faso and Guinea, West Africa, Agricultural Economics $13: 1-9$.

Bakh, M. E. and Islam, M.S., 2005.Technical and Allocative Efficiency of Growing Wheat in Northwest Districts in Bangladesh, Bangladesh Journal of Agricultural Economics, 28(1\&2):73-83.

Baidu, J., 1999. Factors Influencing Adoption of Land-enhancing Technology in the Sahel: Lessons from a Case Study in Niger, Agricultural Economics, 20:231-239.

Batz, F.J., Peters, K.J., Janssen, W., 1999. The Influence of Technology Characteristics on the Rate and Speed of Adoption, Agricultural Economics, 21:121-130.

BBS, 2013. District Statistics Report, Bangladesh Bureau of Statistics, Ministry of Planning, Government of the People's Republic of Bangladesh, Dhaka.

BBS, 2014. Statistical Pocketbook Bangladesh, Bangladesh Bureau of Statistics, Ministry of Planning, Government of the People's Republic of Bangladesh, Dhaka.

Forson, B.J., 1999. Factors Influencing Adoption of Land-enhancing Technology in the Sahel: Lessons from a Case study in Niger, Agricultural Economics, 20:231239.

Gebresilassie, L., and Bekele, A., 2014. Factors Determining Allocation of Land for Improved Wheat Variety by Smallholder Farmers of Northern Ethiopia, Agricultural Economics, 7(3):105-112.

Grisley, W. and Mwesigwa, D. 1994. Socio Economic Determinants of Seasonal Cropland Fallowing Decisions: Small Holders in South-Western Uganda,
Journal of Environmental Management, 42:81-89.

Gujarati, D. N., Porter, D.C. and S. Gunasekar. 2012. Basic Econometrics, Fifth Edition, Tata McGraw Hill Education Private Limited, New Delhi, India.

Hasan, M. K. and Islam, S. M. F., 2010. Technical Inefficiency of Wheat Production in Some Selected Areas of Bangladesh, Bangladesh Journal of Agricultural Resources, 35(1):101-112.

IRRI, 2014. International Rice Research Institute, Annual Report, 2014.

Kamruzzaman, M., and Islam, M. H., 2008. Technical Efficiency of Wheat Growers in Some Selected Sites of Dinajpur District of Bangladesh, Bangladesh Journal of Agricultural Research, 33(3):363-373.

Karim, M. R., Awal, M. A., Akther, M., 2010. Forecasting of Wheat Production in Bangladesh, Bangladesh Journal of Agricultural Research, 35(1):17-28.

Kaur, M., Mahal, A. K., Sekhon, M. K., Kingra, H.S., 2010. Technical Efficiency of Wheat Production in Punjab: A Regional Analysis, Agricultural Economics Research Review, 23:173-179.

Maddala, G. S. 1983. Limited-Dependent and Qualitative Variables in Economics, New York: Cambridge University, Press, pp. 257-91.

McDonald, J.F. and Moffin, R.A., 1980. The Uses of Tobit Analysis, Review of Economics and Statistics, 62:318-321.

Mudasser, M., Hussain, I., Aslam, M. 2001. Constraint to Land-and Water Productivity of wheat in India and Pakistan: A Comparative Analysis, International water Management Institute, 1-36 pp.

Mussei, A., Mwanga, J., Mwangi, W., Verkuijl, H., Mongi, R. Elanga, A., 2001. Adoption of Improved Wheat Technologies by 
Small-Scale Farmers in Mbeya District, Southern Highlands, Tanzania. International Maize and Wheat Improvement Center (CIMMYT), Addis Ababa, Ethiopia, 1-36 pp.

Nowak, P., 1992. Why Farmers Adopt Production Technology, Journal of Soil Water Conservation, 47:14-16.

Poison, R.A. and Spencer, D.S.C., 1991. The Technology Adoption Process in Subsistence Agriculture: The Case of Cassava in South Western Nigeria, Agricultural System, 36:65-77.

Strauss, J., Babosa, M., Teixeira, S., Thomas, D. and Gomes, R., 1991. Role of Education in Adoption of Technology: A Study of Upland Rice and Soybean Farmers in Central-West Brazil, Agricultural Economics, 5:341-359.

Rahman, K. M. M., Quddus, M. A., Haque, M.E., 2002. Estimation of Gross and Net Technical Efficiencies of Wheat Production in Bangladesh under Two Alternative Functional Forms, Bangladesh Journal of Agricultural Economics, 25:85-101.

Rahman, S. 2003. Environmental Impacts of Modern Agricultural Technology Diffusion in Bangladesh: An Analysis of Farmers' Perceptions and their Determinants, Journal of Environmental Management, 68:183-191.
Ransom, J.K., Paudyal, K., Adhikari, K., 2003. Adoption of Improved Maize Varieties in the Hills of Nepal, Agricultural Economics, 29:299-305.

Tasnim, Z. Hafeez, G.ASM., Majumder, S., 2015. Climate Change and Wheat Production in Drought Prone Areas of Bangladesh - A Technical Efficiency Analysis, Journal of Agricultural Science, 7(1):43-53.

Tobin, J. 1958. Estimation of Relationships for Limited Dependent Variables, Econometrica, 26(1): 24-36.

Tripathi, R.S., Raju R. and Thimmappa, K. 2013. Impact of Zero Tillage on Economics of Wheat Production in Haryana, Agricultural Economics Research Review, 26(1):101-108.

Wilson, P., Hadley, D., Asby, C. 2001.The Influence of Management Characteristics on the Technical Efficiency of Wheat Farmers in Eastern England, Agricultural Economics, 2:329-338.

Wubeneh, N.G. 2001. Farm-level Adoption of Sorghum Technologies in Tigray, Ethiopia. Masters Thesis. Purdue University, West Lafayette, USA. 